\title{
Visual Feedback Teaching Aid in Improving Push Pass Technique among Low-Skilled Physical Education Trainee Teachers
}

\author{
Mohd Rizal Bin Mohtar1,2, Denise Koh' \\ ${ }^{1}$ Faculty of Education, Universiti Kebangsaan Malaysia (UKM), Bangi, Malaysia \\ ${ }^{2}$ Teacher Training Institute, Islamic Education Campus, MOE, Bangi, Malaysia \\ Email: denise.koh@ukm.edu.my, P89320@siswa.ukm.edu.my
}

How to cite this paper: Mohtar, M. R. B., \& Koh, D. (2019). Visual Feedback Teaching Aid in Improving Push Pass Technique among Low-Skilled Physical Education Trainee Teachers. Creative Education, 10, 30913100.

https://doi.org/10.4236/ce.2019.1012233

Received: November 7, 2019

Accepted: November 26, 2019

Published: November 29, 2019

Copyright $\odot 2019$ by author(s) and Scientific Research Publishing Inc. This work is licensed under the Creative Commons Attribution International License (CC BY 4.0).

http://creativecommons.org/licenses/by/4.0/

\begin{abstract}
This is an action research study that summarizes one teacher's journey in modifying a conventional soccer skill unit, using a visual feedback teaching aid, in improving soccer push pass technique among low-skilled Physical Education trainee teachers. This is an action research, aimed to improve the push pass technique among seven (7) low-skilled physical education core elective students in one of the teacher education institute in Malaysia. These seven students failed to demonstrate the minimal skill set for a push pass during a conventional class. Preliminary data showed that these students were weak at most of the 10 performance indicators for a push pass, and also scored low for accuracy of the kick. My college and I used a specially designed teaching aid LiLeBo that functions like a portable indoor golf green putting mat, to help students practice the push pass using the correct technique. Evaluation of the push pass is based on their execution (technique) and accuracy. Technique is measured based on teacher observation (based on 10 performance criteria) and accuracy on whether the ball reaches the goal. Students were evaluated based on 5 attempts with the push pass. Evaluation was carried out at the end of eight (8) weeks. Findings from this study showed a positive improvement in both technique and accuracy during the execution of a push pass. This study showed that visual feedback is important to learn correct technique for motor skills, especially among weaker adult students.
\end{abstract}

\section{Keywords}

Soccer Push Pass Technique, Physical Education, Action Research

\section{Introduction}

The ultimate objective of Physical Education (PE) is to equip students with a 
skill set to lead an active lifestyle, a crucial element in fighting against rising obesity among school children in Malaysia. As part of the PE curriculum, students are taught basic movement skills and as they progress, specific sporting skills, so as to enable the students to participate in these sports, either socially or seriously, as they get older or their skill progresses. Therefore, all PE teacher training programmes will include elements where the trainee teachers have to learn common sporting skills in Malaysia.

Soccer is known as the national game in Malaysia, and is included as part of the PE curriculum. All PE trained teachers must be able to demonstrate basic soccer skills. As a lecturer in a teacher's training college specialized in PE, I have to teach basic soccer skills to all pre-service PE teachers. However, I noticed that this semester, after completing the soccer push pass technique with my class, a number of students still could not demonstrate the minimum required competency in this technique. A push pass technique is also known as an inside foot kick, it allows a player to send the ball to a friend with the highest accuracy compared to using the top of the foot and or the outside of the foot (Levanon \& Dapena, 1998). The conventional teaching strategies include a demonstration, group practice and end with an evaluation of their competency, completed over 4 weeks. Minimum required competency is defined here as being able to accurately kick a ball with the correct push pass technique into the target.

I found that some of the students could not master the soccer push pass adequately with the conventional teaching strategies. I also noticed that they did not perform well in the conventional class during group practice sessions when they had to perform the push pass technique with a partner. When these low-skilled students have no confidence in themselves, they would lose motivation to practice. I have therefore, teamed up with a colleague to come up with effective strategies to help these low-skilled students. We believe that teaching aids can be used in this instance, and that an effective teaching aid can increase the students' and build confidence while learning a skill (Ong \& Zamri Mahamod, 2017), stimulate students' interest (Halizah Hamzah, 2009; Mahamod, 2011), and build confidence (Ahmad Fikri Rahman, 2019).

The research of this action study aims to improve the soccer push pass technique and accuracy of low-skilled PE teacher trainee, by giving specific verbal feedback (from the teacher) and allowing self-practice using a teaching aid that provides visual feedback (LiLeBo) before progressing to practicing with a partner.

\section{Setting}

The students involved in this study are PE trainee teachers specializing in primary pedagogy. These teacher trainees will be qualified primary teachers specializing in teaching PE at schools. At the end of the four weeks conventional lessons on push pass technique, I found that seven out of 13 students in class still 
could not demonstrate the minimum requirement of a push pass. Therefore, these seven students were selected to participate in this action research, where I attempt to help them master the push pass technique. Table 1 below shows the overall marks for all students in the conventional class. Students who scored less than $50 \%$ on both technique and accuracy were included in this action research (Creswell, 2018). Therefore, student P1, P4, P6, P7, P9, P10, and P11 were included in this action research. Instep kick is more precise than the toe kick in an unstressed movement (Sorensen et al., 2003).

\section{Methodology}

We designed a specialized teaching aid (LiLeBo) to help these low-skilled students to master the push pass technique for soccer. LiLeBo is an apartus similar to an indoor golf green putting mat. If the ball manages to enter the target, a score will be displayed as a reward. Each successful kick (ball reaches goal) will be given one point and each touch on the ramp will have a point deducted. This game-like teaching aid is designed to allow students to practice individually and still get feedback, and at the same time, increase student's interest in doing the practice with this game-like teaching aid. Having complete focus during lessons can increase the students' confidence level, especially when they can complete the task on their own (Ali \& Sahal, 2016).

The role of the teacher was also modified. Where in the conventional lesson, my role in class was like a facilitator, walking around the class after delivery of the correct push pass technique, and giving feedback only when necessary. Students practice in pairs during the conventional lessons, and receive feedback from their partners. Therefore, the teachers' role in the conventional lesson were minimal after the initial "teaching" session. However, during this intervention, the teacher played a more active role in giving verbal feedback (both positive and

Table 1. Scores for execution of a push pass technique and accuracy among PE major students. All students were given 5 tries and each try will be scored.

\begin{tabular}{cccccc}
\hline Student ID & Accuracy scores & $\%$ & Technical Scores & $\%$ & Notes \\
\hline P1 & $1 / 5$ & $20 \%$ & $4 / 10$ & $40 \%$ & poor \\
P2 & $3 / 5$ & $60 \%$ & $5 / 10$ & $50 \%$ & moderate \\
P3 & $3 / 5$ & $60 \%$ & $5 / 10$ & $50 \%$ & moderate \\
P4 & $2 / 5$ & $40 \%$ & $4 / 10$ & $40 \%$ & poor \\
P5 & $3 / 5$ & $60 \%$ & $5 / 10$ & $50 \%$ & moderate \\
P6 & $1 / 5$ & $20 \%$ & $4 / 10$ & $40 \%$ & poor \\
P7 & $1 / 5$ & $20 \%$ & $4 / 10$ & $40 \%$ & poor \\
P8 & $3 / 5$ & $60 \%$ & $5 / 10$ & $50 \%$ & moderate \\
P9 & $2 / 5$ & $40 \%$ & $4 / 10$ & $40 \%$ & poor \\
P10 & $1 / 5$ & $20 \%$ & $4 / 10$ & $40 \%$ & poor \\
P11 & $2 / 5$ & $40 \%$ & $4 / 10$ & $40 \%$ & poor \\
P12 & $4 / 5$ & $80 \%$ & $9 / 10$ & $90 \%$ & Excelent \\
P13 & $5 / 5$ & $100 \%$ & $9 / 10$ & $90 \%$ & Excelent \\
\hline
\end{tabular}


negative) while the students were practiving their push pass technique with $\mathrm{Li}$ LeBo. Feedback were given based on the 10 performance criteria for a push pass.

There were two cycles to this action study. The first cycle aimed to create a friendly and fun environment for the students to practice their push pass technique. Using LiLeBo as a teaching aid, we believe that the environment is more friendly because these low-skilled students can practice on their own without pressure to perform in front of their friends. Further, LiLeBo injects some "fun" with its game like feedback responses to the ball when it touches parts of LiLeBo. Practice time remained the same as the conventional class at 30 minutes once a week. The teacher would give specific feedback based on the 10 performance criteria directly to the students while they were practicing. Feedbacks were not given during evaluation.

At the end of cycle 1, we noticed that although there were improvements in the technical scores and accuracy scores, the execution of the skill was still not smooth and still have low accuracy. As these were low-skilled students, we believe more practice time was needed, as well as the need to include some other strategies to build their confidence. Accurate passing is important for maintaining possession of the ball and for setting up goal scoring opportunities in a team sport (Rampinini et al., 2008).

In cycle 2, the practice session per week was increased from 30 minutes to 60 minutes. During cycle 2, LiLeBo was no longer used extensively. Students are now put in practice sessions in a group, where they will pass the ball between them using the push pass technique. This activity puts the practicing into the context of a soccer game, and thus, hopefully will improve their achievement and build confidence (Suryawati \& Osman, 2018). This activity is called "monkey play", and performed in groups of 3 to 4 . One group member is identified to be the "monkey". The rest of the group members must pass the ball to each other using the push pass technique. If the "monkey" manages to intercept the passing ball, then the last person who kicked will be the "monkey" The cooperative learning method used should be appropriate to the student acceptance level to aim at enhancing student achievement in improving the level of understanding, problem solving skills and to stimulate learning while fostering social interaction between pupil and teacher (Somasudram et al., 2017) (Figure 1).

\section{Measures}

The push pass technique and accuracy were measured during baseline (conventional lessons), and after each cycle. Push pass technique were measured using a performance indicator checklist. The tester observe the students perform a push pass to a target. The performance was evaluated based on the 10 performance criteria by Luxbacher (2005), refer to Table 2. Accuracy was measured based on the outcome of the push pass. If the ball hit the target, a point is given. Each students is allowed 5 tries, there for the total points for accuracy is 5 points (one point for each try), and for technical performance is 50 points ( 1 point for each technical demonstrated -10 technical performance indicators in total over 5 tries). 


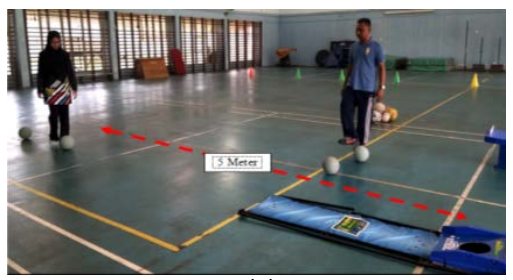

(a)

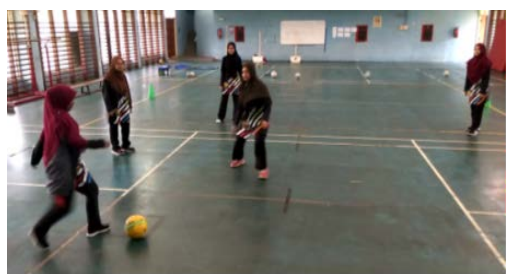

(c)

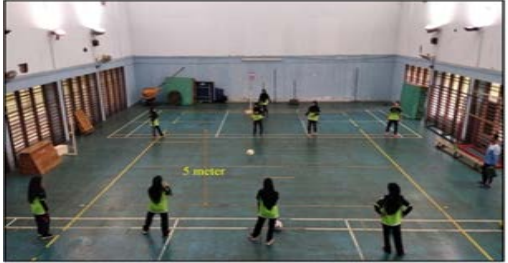

(e)

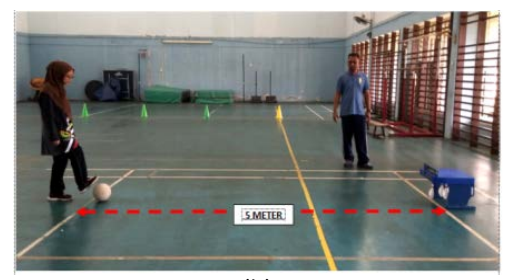

(b)

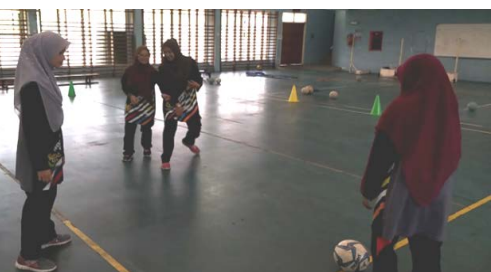

(d)

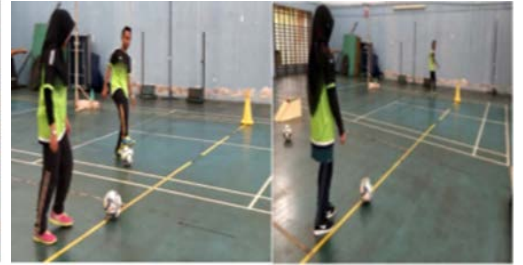

(f)

Figure 1. Cycle 1: (a) Practicing with LiLeBo to improve technique (b) Practicing with LiLeBo to improve accuracy; Cycle 2: (c) (d) Additional element of practiving with friends; (e) Evaluation of technique; (f) Evaluation of accuracy.

Table 2. Technical Performance Indicator used in this study.

\begin{tabular}{cl}
\hline No. & \multicolumn{1}{c}{ Performance Indicator } \\
\hline 1 & Position ready and See the target \\
2 & Approach the ball. \\
3 & $\begin{array}{l}\text { Plant and position of support, or non-kicking foot (the toe of the non-kicking foot should } \\
\text { be pointed in the direction the player wants the ball to go). }\end{array}$ \\
4 & Look at the ball, holding the head steady. \\
5 & Contact the correct area of the ball with a locked ankle. \\
6 & Kick with the inside of the foot \\
7 & Front of foot pointed upwards \\
8 & Kick in the middle of the ball \\
9 & Follow-through: kick "through the ball," following through toward the target \\
10 & Transfer the weight forward.
\end{tabular}

adapted from Luxbacher, 2005.

\section{Results}

\subsection{Baseline}

The first evaluation is after the conventional lessons. We found that most students did not look at the ball while kicking, did not lock the ankle, poor aim of the ball (did not kick in the middle of the ball), and no follow through (refer to 
Table 3). Individual scores are also presented in Table 4. Based on these baseline data, we can give individualized verbal feedback during practice to help the student demonstrate the correct technique while doing the push pass in class.

For example, $\mathrm{P} 1$ was chosen to participate in this study as remedial class because he failed to demonstrate the minimum technical requirement for a push pass, which is set at $50 \%$. Therefore, during practice sessions with LiLeBo, I will specifically observe and give feedback on his approach, where he is looking, whether he locked his knee during the contact with ball, direction of the front of

Table 3. Overall technical performance scores for the whole class.

\begin{tabular}{cllc}
\hline No. & \multicolumn{1}{c}{ Performance Indicator Rubric } & $\begin{array}{c}\text { Technical } \\
\text { Performance Score }\end{array}$ & $\begin{array}{c}\text { Percentage } \\
(\%)\end{array}$ \\
\hline 1 & Position ready and See the target & 13 & $100 \%$ \\
2 & Approach the ball & 9 & $69 \%$ \\
3 & $\begin{array}{l}\text { Plant and position non-kicking foot pointed towards the } \\
\text { direction of the ball projectile) }\end{array}$ & 13 & $100 \%$ \\
4 & Look at the ball, holding the head steady. & 3 & $23 \%$ \\
5 & Contact the correct area of the ball with a locked ankle. & 4 & $31 \%$ \\
6 & Kick with the inside of the foot & 12 & $92 \%$ \\
7 & Front of foot pointed upwards & 5 & $38 \%$ \\
8 & Kick in the middle of the ball & 5 & $38 \%$ \\
9 & Follow-through & 2 & $15 \%$ \\
10 & Transfer weight forward. & 9 & $69 \%$ \\
\hline
\end{tabular}

Table 4. Individual scores for technical performance indicators.

\begin{tabular}{|c|c|c|c|c|c|c|c|c|c|c|c|c|c|c|}
\hline \multirow{2}{*}{ No. } & \multirow{2}{*}{ Technical Performance Indicator } & \multicolumn{13}{|c|}{ Target group } \\
\hline & & P1 & P2 & P3 & P4 & P5 & P6 & P7 & P8 & P9 & P10 & P11 & P12 & P13 \\
\hline 1 & Position ready and See the target & I & I & I & l & l & I & I & I & l & I & I & l & I \\
\hline 2 & Approach the ball. & & I & I & I & I & & & I & I & & & I & l \\
\hline 3 & $\begin{array}{l}\text { Plant and position non-kicking } \\
\text { foot pointed towards the direction } \\
\text { of the ball projectile) }\end{array}$ & I & / & I & I & I & I & I & I & l & I & I & l & I \\
\hline 4 & $\begin{array}{l}\text { Look at the ball, holding the head } \\
\text { steady. }\end{array}$ & & I & & & & & & & & & & I & l \\
\hline 5 & $\begin{array}{l}\text { Contact the correct area of the ball } \\
\text { with a locked ankle. }\end{array}$ & & & I & & & & & I & & & & l & l \\
\hline 6 & Kick with the inside of the foot & I & I & I & l & I & I & I & I & l & & I & I & I \\
\hline 7 & Front of foot pointed upwards & & I & I & & I & & & l & & & & & l \\
\hline 8 & Kick in the middle of the ball & & & & & & I & I & & & I & & I & I \\
\hline 9 & Follow-through & & & & & & & & & & & & l & I \\
\hline 10 & Transfer the weight forward. & I & I & I & & I & & & l & & I & l & I & l \\
\hline & Total & 4 & 7 & 7 & 4 & 6 & 4 & 4 & 7 & 4 & 4 & 4 & 9 & 10 \\
\hline
\end{tabular}


foot, position of contact with the ball, and whether there was follow-though. These technicalities were not demonstrated during the conventional class, therefore, will be emphasized in this remedial class. At the same time, teaching aid LiLeBo will provide visual feedback on the outcome of that kick.

\subsection{Cycle 1}

At the end of the first cycle, a standard evalution was carried out to measure the technical performance and accuracy of the students. Most (five out of seven) students showed an improvement in technical performance score, from an average of 20 to an average of 23.4 (range: 20 -28). However, with a total score of 50, an average of 23.4 is not high and shows that there is still room for improvement. As for accuracy, three out of seven students showed an improvement in accuracy, from two out of five tries hitting the target, to three out of five. The other students showed no change in accuracy score (refer to Table 5).

\subsection{Cycle 2}

Based on the results from cycly one, only two out of seven students reached the minimal 50\% scores on both technical performance and accuracy. Therefore, a second cycle was conducted to attempt to push everyone to achieve the minimum of $50 \%$. For the cycle 2, the practice time was increased from 30 minutes per week to 60 minutes per week. At the same time, to stimulate testing condition, the teaching aid was removed and group activity was introduced. At the end of cycle 2, all seven students had scores for both technical performance and accuracy above $50 \%$. The average technical performance scores were 36.4 (range: 30 - 40) and accuracy score at 3.6 (range: 3 - 4) (refer to Table 5).

Overall, after two cycles of intervention, all the students who could not demonstrated at least $50 \%$ competency for both technical performance and accuracy during conventional lessons for the soccer push pass were able to achieve average scores of above $50 \%$. This shows that the intervention implemented among these seven low-skilled trainee teachers were effective in improving their push pass technique and accuracy.

\section{Discussion}

There is a saying that goes "Practice does not make perfect. Perfect practice makes perfect". The findings of this study show that the correct teaching aid can improve the learning of motor skills among low-skilled teacher trainees. Verbal and visual feedback during practice is helpful in correcting technical mistakes as well as improve accuracy of a push pass. We believe that innovative teaching aids can enhance the learning of motor skills and help students develop the right techniques (Pišot, 2012). When teaching aid is aligned with students' abilities, it will greatly help with the teaching and learning process Husdarta (2009).

The improvement in both technical performance and accuracy of the push pass exemplified the positive and consistent change that was expected at the end 
Table 5. Individual total scores for technical performance and accuracy of the push pass.

\begin{tabular}{|c|c|c|c|c|c|c|c|c|}
\hline \multirow[b]{2}{*}{ No. } & \multirow[b]{2}{*}{$\begin{array}{l}\text { Student } \\
\text { ID }\end{array}$} & \multirow[b]{2}{*}{$\begin{array}{l}\text { Dominant } \\
\text { Leg }\end{array}$} & \multicolumn{2}{|c|}{ Baseline } & \multicolumn{2}{|c|}{ Cycle 1} & \multicolumn{2}{|c|}{ Cycle 2} \\
\hline & & & $\begin{array}{l}\text { Accuracy } \\
\text { (5 points) }\end{array}$ & $\begin{array}{l}\text { Technique } \\
\text { (50 points) }\end{array}$ & $\begin{array}{l}\text { Accuracy } \\
\text { (5 points) }\end{array}$ & $\begin{array}{l}\text { Technique } \\
\text { (50 points) }\end{array}$ & $\begin{array}{l}\text { Accuracy } \\
\text { (5 points) }\end{array}$ & $\begin{array}{l}\text { Technique } \\
\text { (50 points) }\end{array}$ \\
\hline 1 & P1 & Right & 2 & 20 & 3 & 24 & 4 & 40 \\
\hline 2 & P4 & Left & 2 & 20 & 2 & 22 & 4 & 35 \\
\hline 3 & P6 & Left & 2 & 20 & 3 & 28 & 3 & 40 \\
\hline 4 & P7 & Right & 2 & 20 & 2 & 20 & 4 & 30 \\
\hline 5 & P9 & Right & 2 & 20 & 3 & 28 & 4 & 35 \\
\hline 6 & P10 & Left & 2 & 20 & 2 & 20 & 3 & 40 \\
\hline 7 & P11 & Left & 2 & 20 & 2 & 22 & 3 & 35 \\
\hline
\end{tabular}

of the intervention. What was not expected was the low rate of improvement at the end of cycle 1 . The major improvements at the end of cycle 2 that was pbserved in this study may be due to the increased practice sessions (Yamada et al., 2019). Not all students are able to focus and understand the teaching style such as instruction, explanation, teacher demonstration at the Physical Education teaching session in the field.

PE teachers that can demonstrate the correct technique in a sport skills are better equipt to teach PE in schools. PE teachers should be able to demonstrate the interaction between the physical properties of the movement by using their experience and knowledge in quality teaching so that students are more motivated to learn a skill especially among low-skilled students. Previous study has found that verbal and visual cues enhances perceptual representation and retention of the skeill and improve taks reproduction capabilities (Janelle et al., 2003). Teachers who can provide such cues are more likely to create a learning environment that is much more condusive to learning, especially among young children (primary school children). The learning process was exciting and meaningful to the children by engaging in teaching approach through to play (Puteh, 2010).

Future studies should explore incorporating innovative movements (for example animal inspired movements) that can support a particular sport skills. This type of activities will expose these PE trainee treachers to teaching ideas that they can adopt and adapt when they are teaching PE in schools later on.

\section{Conclusion \& Self Reflection}

The use of LiLeBo in this action study was seen to indirectly change my teaching practice and also to maximize my students' learning focus on the skills to be mastered. Although this study took a long time to come up with an innovation tool, it is seen as an investment in my teaching for this course as I will continue to use and customize these tools for Elementary Physical Education trainee teachers in the next cohort. 
The varying levels of ability and experience of the students were a challenge for me as they encouraged me to think critically and creatively to reflect the best teaching practices in practical teaching. With that in mind, I hope to re-plan my semester for the course in the coming semester. Writing my reflections during the first week of teaching, I found it difficult to teach this course because nearly $85 \%$ of the students in this class were female and almost all of them had no history of involvement in sports, especially in soccer. However the results of this action study gave a positive result to my research goal of doing the right and safe and accurate technique towards the target. Other identified factors, weaknesses in movement skills and lack of knowledge of physical literacy also make the skills impossible.

I also find that the effectiveness of using this tool to innovate can provide the confidence and adaptability of the study's goals when performing consistent inside foot kick techniques in any environment or situation. In addition to testing course learning outcomes for behaviorally-based behavioral changes to look at psychomotor, cognitive and affective domains I also hope that Physical Education courses offered at the Institute of Teacher Education (IPG) can provide knowledge and experience to enable future teachers to have basic knowledge and skills related to the teaching profession. Soccer is not played by women as well, and female teacher need to have the necessary knowledge and skills to effectively teach these skills, and ensure that women soccer in Malaysia continue to thrive (Ahmad Fikri Rahman, 2019).

\section{Acknowledgements}

This research was partially supported by grant received from the Faculty of Education, Universiti Kebangsaan Malaysia code PP-FPEND-2019.

\section{Conflicts of Interest}

The authors declare no conflicts of interest regarding the publication of this paper.

\section{References}

Ahmad Fikri Rahman, Z. M. (2019). Teknik lakaran bersama peta alir I-Think meningkatkan kemahiran menjana idea murid etnik Lun Bawang dalam karangan autobiografi. Jurnal Pendidikan Bahasa Melayu, 9, 12-22.

Ali, M. M., \& Sahal, N. (2016). Intervensi Meningkatkan Tumpuan dalam Pembelajaran Murid Bermasalah Pembelajaran. Jurnal Pendidikan Malaysia, 41, 1-6.

Creswell, J. D. (2018). Research Design Qualitative, Quantitative, and Mixed Methods Approaches (5th ed.). [Thousand Oaks, CA: SAGE Publications, Inc.

Husdarta, H. J. S. (2009). Manajemen Pendidikan Jasmani. Bandung: Alfabeta.

Janelle, C. M., Champenoy, J. D., Coombes, S. A., \& Mousseau, M. B. (2003). Mechanisms of Attentional Sueing during Observational Learning to Facilitate Motor Skill Acquisition. Journal of Sports Sciences, 21, 825-838.

https://doi.org/10.1080/0264041031000140310 
Levanon, J., \& Dapena, J. (1998). Comparison of the kinematics of the full-instep and pass kicks in soccer. Medicine and Science in Sports and Exercise, 30, 917-927. https://doi.org/10.1249/00005768-199806000-00022

Luxbacher, J. (2005). Soccer: Steps to Success (3rd ed.). Champaign, IL: Human Kinetics.

Ong, S. C., \& Zamri Mahamod, M. I. M. H. (2017). Meneroka Kaedah Pengajaran Guru Cemerlang Bahasa Melayu Negeri Sarawak: Satu Kajian Kes. Jurnal Pendidikan Bahasa Melayu, 7, 93-108.

Pišot, R. (2012). Lifelong Competency: Model of Motor Development. Kinesiologia Slovenica, 3, 35-46.

Puteh, S. N. (2010). The Play Approach in Teaching Language and Literacy for Preschool Education. Pendidikan Bahasa Melayu, 1, 1-15.

Rampinini, E. et al. (2008). Effect of Match-Related Fatigue on Short-Passing Ability in Young Soccer Players. Medicine and Science in Sport and Exercise, 40, 934-942. https://doi.org/10.1249/MSS.0b013e3181666eb8

Somasudram, B., Dan, \& Mahamod, Z. (2017). The Effectiveness of Cooperative Learning Towards Achievement and Students Motivation Secondary School in Malay Language Learning. Malay Language Education Journal, 7, 2180-4842.

http://journalarticle.ukm.my/10409/1/128-246-1-SM.pdf

Suryawati, E., \& Osman, K. (2018). Contextual Learning: Innovative Approach towards the Development of Students' Scientific Attitude and Natural Science Performance. Eurasia Journal of Mathematics, Science and Technology Education, 14, 61-76.

https://doi.org/10.12973/ejmste/79329

Yamada, C., Itaguchi, Y., \& Fukuzawa, K. (2019). Effects of the Amount OD Practice and Time Interval between Practice Sessions on the Retention of Internal Models. PLoS ONE, 144, e0215331. https://doi.org/10.1371/journal.pone.0215331 